\title{
CCCC and LASER-TEC laser eye safety experiment/lab
}

\section{Matthew Zannini, Gary Beasley, Chrys Panayiotou}

Matthew Zannini, Gary Beasley, Chrys Panayiotou, "CCCC and LASER-TEC laser eye safety experiment/lab," Proc. SPIE 11143, Fifteenth Conference on Education and Training in Optics and Photonics: ETOP 2019, 111433F (2 July 2019); doi: 10.1117/12.2523713

SDIE Event: Fifteenth Conference on Education and Training in Optics and Photonics: ETOP 2019, 2019, Quebec City, Quebec, Canada 


\title{
CCCC \& LASER-TEC Laser Eye Safety Experiment/Lab
}

\author{
Matthew Zannini*a ${ }^{\text {,a }}$, Gary Beasley ${ }^{\mathrm{b}}$, Chrysanthos Panayiotou ${ }^{\mathrm{c}}$ \\ ${ }^{a}$ Central Carolina Community College, 1075 E. Cornelius Harnett Blvd, Lillington, NC, USA 27546; \\ ${ }^{\mathrm{b}}$ Central Carolina Community College, 1075 E. Cornelius Harnett Blvd, Lillington, NC, USA 27546; \\ 'LASER-TEC NSF ATE Grant, Indian Rivers State College, 3209 Virginia Ave., Fort Pierce, FL, \\ USA 24981-5596
}

\begin{abstract}
Laser eye safety is one of the most important topics covered in any laser curriculum. Before students begin working hands-on with laser labs, it is extremely critical for students to understand safe methods to observe when using and operating lasers. Since the eye is the most vulnerable body part to laser energy damage, it is important for students to have a good understanding of how the eye may be damaged by laser energy, and how to protect it from laser energy. Typically, students studying laser safety learn about laser eye safety by studying parts of the eye, wavelength relationships with damage to different eye parts, magnification relationships, and interacting irradiance levels and wavelengths. The curriculum material and tools generally used by students studying laser eye safety only involves ANSI standards, technical explanations, pictures and equations. Central Carolina Community College and LASER-TEC have developed a Laser Safety Eye Lab to provide students an additional learning tool for studying this topic. The lab includes the use of a sheep eye for demonstrating the interactions between various parts of the eye and different aspects of laser energy, including coherence, irradiance, with respect to wavelength variations. This lab will provide students a hands-on learning experience of all the important interactions of the eye and laser energy relative to laser eye safety.
\end{abstract}

LASER-TEC Co-PI Gary Beasley, Central Carolina CC, and Chrys Panayiotou, LASER-TEC PI will share the new lab. A copy of the presentation will be shared with all participants.

Keywords: Laser, Safety, Retina, Absorption,

\section{INTRODUCTION}

Safety in the Laser and Photonics field is one of, if not the most important matters to educate workers, and students. The field of laser and photonics technology is always changing at an astonishing pace. The importance of having trained technicians, who are capable of learning and contributing to the progress and sustainment of this field is only possible if each and every person knows the fundamentals of safety, and the very real dangers that exist when working with lasers.

To ensure that all students, and future technicians are prepared to enter the workforce, and perform safely and effectively, Central Carolina Community College Laser and Photonics Technology (LPT) program focuses heavily on the fundamentals of human eye anatomy, laser safety, and its applications. These factors are taught through extensive lecture, as well as comprehensive labs. Students are tested on the topic of laser safety and its immeasurable impacts on health and safety.

Collaboration with the Biology department has resulted in a hands-on lab consisting of the examination, dissection and identification of sheep, and cow eyes. This hands-on dissection helps to further the fundamental understanding of the anatomy of the human eye and how it pertains to the safe operation of lasers.

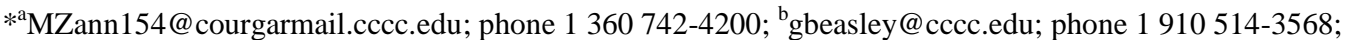

${ }^{*}$ c cpanayio@irsc.edu; phone 1772 462-7621
}

Fifteenth Conference on Education and Training in Optics and Photonics: ETOP 2019, edited by

Anne-Sophie Poulin-Girard, Joseph A. Shaw, Proc. of SPIE Vol. 11143, 111433F · C 2019

SPIE, ICO, IEEE, OSA · CCC code: 0277-786X/19/\$18 · doi: 10.1117/12.2523713 
This collaboration could be taken one step further by combining the real-world lab using the eye of a sheep or cow, and the laser labs that are used to teach the various factors that contribute to laser safety. The idea is to use the various lasers to illustrate the possible damage the can be caused by the improper use, and operation of a laser. The hope is that each student will develop a deeper understanding of both the anatomy and function of the eye, as well as the importance of using proper safety procedures, to avoid damage.

Again, the safety of the human operator is the most important factor in the world of lasers. Laser energy can be as small as milliwatts, upwards more than megawatts. When light from a laser comes into contact with a material, some of the laser energy maybe absorbed. If this material is skin, it can result in burns. As painful and unsightly as a burn maybe it is often times temporary. The most venerable part of the human body is the human eye. The following paper will discuss the factors which contribute to the dangers of laser and the development of the lab in which the fundamentals of laser safety will be emphasized by illustrating the damage done to the retina of a cow and sheep eye.

\section{LASER-TEC NSF ATE GRANT}

\section{Background}

The Center for Laser and Fiber Optics Education, LASER-TEC, is a National Science Foundation Advanced Technological Education Center comprised of community and state colleges, universities, high schools and technical centers, trade associations, and laser and fiber optic (LFO) companies.

Headquartered in Fort Pierce, Florida, LASER-TEC started its operation in September 2013 with the goal of developing a sustainable pipeline of qualified laser and fiber optics technicians to meet the industry demand across the southeast region.

To achieve our goal, LASER-TEC is committed to assisting colleges and high schools with creating and offering courses in lasers and fiber optics.

CCCC is a Co-PI in the LASER-TEC grant. The grant funded development of this sheep eye laser safety experiment through the purchase of some of the consumable materials used in the lab.

\section{PROBLEM STATEMENT}

\section{Laser Eye Safety Education}

The following topics are covered when CCCC LPT students take their first basic laser course. It is important that laser safety is covered prior to the students using lasers in labs. Though covering the material in lecture is important, students are unable to visually see just how delicate the retina is, and how only a small amount of laser energy is required to damage the retina.

\section{Power}

Power is the term most commonly used when addressing the strength of a laser. Power is the measure of the rate at which energy is transferred. The watt $(\mathrm{W})$ is the unit of measure, or alternatively is equal to one joule per second $(\mathrm{J} / \mathrm{sec})$. The average laser pointer has a power of only a few milliwatts. Power alone is not a sufficient metric that can be used to determine the safety of a laser. The amount of space that laser is incident upon plays a key factor as well.

\section{Area}

Area as we all learned in elementary school is the unit of flat two-dimensional space measured in $\mathrm{cm}^{2}$ or in ${ }^{2}$. The area plays an important role in calculating proper laser safety as it relates directly to the irradiance, which is power per unit area. Low power laser incident upon a large area will have a smaller chance of causing permanent damage. One important number used in laser calculations is $7 \mathrm{~mm}$. Seven millimeters is often used as it is considered to be the maximum diameter of a fully dilated human pupil. The formula for area is Area $(A)=\left(\pi \mathrm{d}^{2}\right) / 4$, where "d" is the diameter of the spot the laser is incident upon. Using this knowledge we can move on to arguably the most important metric for laser safety, irradiance. 


\section{Irradiance}

Irradiance is the measure of power per unit of area. It is commonly measured in watts $/ \mathrm{cm}^{2}$. The formula for irradiance is $\mathrm{E}=\mathrm{P} / \mathrm{A}$ resulting in a unit of $\mathrm{W} / \mathrm{cm}^{2}$. This formula is important because we can quickly calculate the actual delivery of energy to a total area, such as that of the human eye, not just the power of the laser, which often times can be seem to be low, but is capable of doing permanent damage to the eye. With the understanding and ability to calculate and measure these factors, there is one other key component to understand. The focusing of the light through the lens and cornea will focus the light into a spot many times smaller than the incident beam diameter, resulting in a much larger irradiance incident upon the retina.

\section{Anatomy of the eye}

The basic anatomy of the eye will be briefly explained, starting from the front (as light would travel) through the cornea, and ending at the retina. Also the significant wavelengths of light that each part are susceptible to will be included.

\section{Cornea}

The cornea is the tough, outer covering of the eye. It absorbs light from 200-400nm and $1400 \mathrm{~nm}$ and above. The cornea will refract light of the visible wavelength from $400-700 \mathrm{~nm}$, which is the spectrum range we see.

\section{Iris}

The iris is responsible for the size of the opening which allows light to enter the eye. This is the measured $7 \mathrm{~mm}$ average diameter that we use for testing purposes. The iris dilates and constricts depending on the amount of light being receives at the retina. One important factor to keep in mind is that the iris only responds to visible light.

\section{Lens}

The lens is another transparent part of the eye. It is composed of flexible tissue that can change its shape in conjunction with the iris, and muscles. The job of the lens is to focus light coming into the pupil onto the retina to form an image. Ultraviolet light below $400 \mathrm{~nm}$ is absorbed by the lens. Of course, $400-700 \mathrm{~nm}$ is passed on to the retina.

\section{Vitreous}

The vitreous is the jellylike substance that fills the eye. It is clean and has an index of refraction of about 1.337. The vitreous humor helps to maintain the shape of the eye so the optical components can property focus light onto the retina.

\section{Retina}

The retina is arguably the most important, and delicate part of the eye. The light entering the pupil is focus by the lens and ultimately falls upon the retina. The retina consists of a thin layer of light sensitive cells that produce a signal that transmits along the optic nerve ultimately resulting in what we know as sight. Visible light is the most dangerous form of light for the retina, as our eye is designed to allow the passage of visible light, and the retina is designed to absorb it. Lasers operating in this visible spectrum, as well as above it upwards of $1400 \mathrm{~nm}$ are very dangerous to the retina.

\section{Choroid}

Inside the eye, there is a lining called the choroid that is dark in color and helps to absorb and reduce internal reflections. This portion of the eye is relatively safe from incoming laser light.

\section{Sclera}

The sclera is the tough white, outer covering of the eye. This is not usually influenced by incoming light in any manner significant when compared to the possible risks to the retina.

\section{Types of beam hazards}

The most notable type of beam hazard that will be discussed is the intra-beam hazard however the other common types will be briefly described. 


\section{Specular reflection}

When light is incident upon a surface, there is usually a certain amount of light that is absorbed, scattered and reflected. The reflected light is one that can potentially be hazardous. If the surface is smooth and mirror like, then a specular reflection could take place. This specular reflection can be almost as hazardous as the incident beam, as very little energy is lost to absorption.

\section{Diffuse Reflection}

The other type of reflection that is significantly less hazardous is known as a diffuse reflection. This occurs when the laser light is incident upon a surface that is rough. The surface is rough and scatters the incident light into many different directions. The energy is spread out. However, the danger is still present with a diffuse refection if the incident laser is high enough power.

\section{Fresnel or Front Surface Reflection}

The testing and use of lasers often require the transmission of a laser though a medium such as glass. This partial refection of a laser is a hazard that must be accounted for. This is known as a Fresnel refection and is similar to a specular reflection, in that the beam is collimated; however the power is significantly less. The danger is still present with a powerful enough beam.

\section{Intra-beam Viewing}

The most severe danger to the eye is the condition known as intra-beam viewing. This is the worst-case scenario in which a coherent, collimated laser beam is incident upon the eye so that the beam is focused through the lens and onto the retina. The focusing of the coherent, collimated laser will concentrate its entire energy onto an area of the retina only microns across. This results in the irradiance being multiplied by approximately 100,000, which can result in permanent immediate damage, even with a relatively weak laser. This is the type of hazard we will be simulated with the lab.

\section{SOLUTION - IMPLEMENTATION OF SHEEP EYE LASER SAFETY LAB}

\section{Overview}

This lab was developed to further the educational benefits of the CCCC LPT program module on eye safety, and the collaboration with the biology department lab on eye anatomy. The impact of the laser damage to actual biological samples will hopefully serve to enhance the educational benefit of both labs. The basic premise of the lab is to isolate the wavelength that each part of the eye is susceptible to, then subject each respective part to that wavelength and make observations. Due to the alterations that take place when cow and sheep eyes are preserved, it is impossible to transmit light through the cornea. For this reason the lens and retina will be removed and tested independently. The samples include a lens from both a cow and sheep eye, as well as a retina from each, divided into two samples each. Retinal samples were subjected to the IPG Diode pumped Ytterbium Fiber laser, with wavelength of $900-1200 \mathrm{~nm}$, and a maximum continuous wavelength output of $25 \mathrm{~W}$. This was selected for retinal testing due to the retina's absorption of this wavelength. Lenses were each tested using the Kimmon Helium-Cadmium laser outputting wavelengths of $325 \mathrm{~nm}$ and $442 \mathrm{~nm}$.

Below is the lab that was developed and completed. The lab includes an introduction, listing materials required, as well as some general background information, followed by a dissection portion, subsequent testing, data collection including tables and comparisons of before and after photographs, and finally finishing with considerations and conclusions. This lab was created with first year laser students in mind, with instructor supervision. The emphasis is not on the measurements of laser output and power but of the end result of the physical destruction to organic tissue that is illustrated.

\section{Sheep Eye Laser Safety LAB \\ Introduction}

This lab was created to help students see how vulnerable the eye is to low energy laser sources, and how laser safety is extremely important! 


\section{Purpose / Objectives:}

- Demonstrate the effects of light on the retina, and lens of an eye.

- Familiarize yourself with the anatomy of the eye.

- Better understand the need for eye safety when using lasers.

\section{Background / Theory / References:}

The human eye is a sensitive organ that allows us to interpret the light of the world around us into signals that can be seen as images. The very light that our eyes depend on to process and create images can also be a source of damage. The situation in compounded tremendously when the use of high-powered lasers are considered. Many of the lasers used in the LPT program are not visible to the human eye. This however is a factor that makes these powerful forms of light even more dangerous. The inability to see and react to the dangerous laser light can make it extremely easy to damage your eye permanently. The purpose of this lab will be to first get a hands-on anatomy lesson of a cow or sheep eye. Using that knowledge and the proper safety procedures we will then illustrate the power absorption and transmission of the Lens, and Retina. The Cornea will most likely not be a viable test subject as preservation causes cloudiness to form. At the end of the lab you should be familiar with the basic structure of the eye and have a good illustration of why you should protect your own eyes.

\section{Software Utilized:}

- Microsoft office or other word processor

- Microscope viewing software

\section{Equipment Required:}

- IPG YLR-10-Y12 (1064nm)

- $\quad \operatorname{HeCd}(325 \mathrm{~nm} \&$ 442nm)

- Appropriate Power Meter

- IR thermometer

- Sheep or Cow Eye (or both)

- Scalpel

- Scissors

- Dissection Tray

- Tweezers

- Pins

- Gloves

- Saline or Distilled water

- Microscope with software integration

\section{Part 1: Anatomy Portion}

1. With the eye on a dissecting tray, remove excess muscle and connective tissue.

2. Cut the eye in half separating the front and back, making sure not to damage the retina, or lens in the process.

3. Separate the iris, and cornea from the lens. While removing excess tissue try not to damage the lens. With the lens separated, set aside by storing in plastic bag with saline or distilled water. 


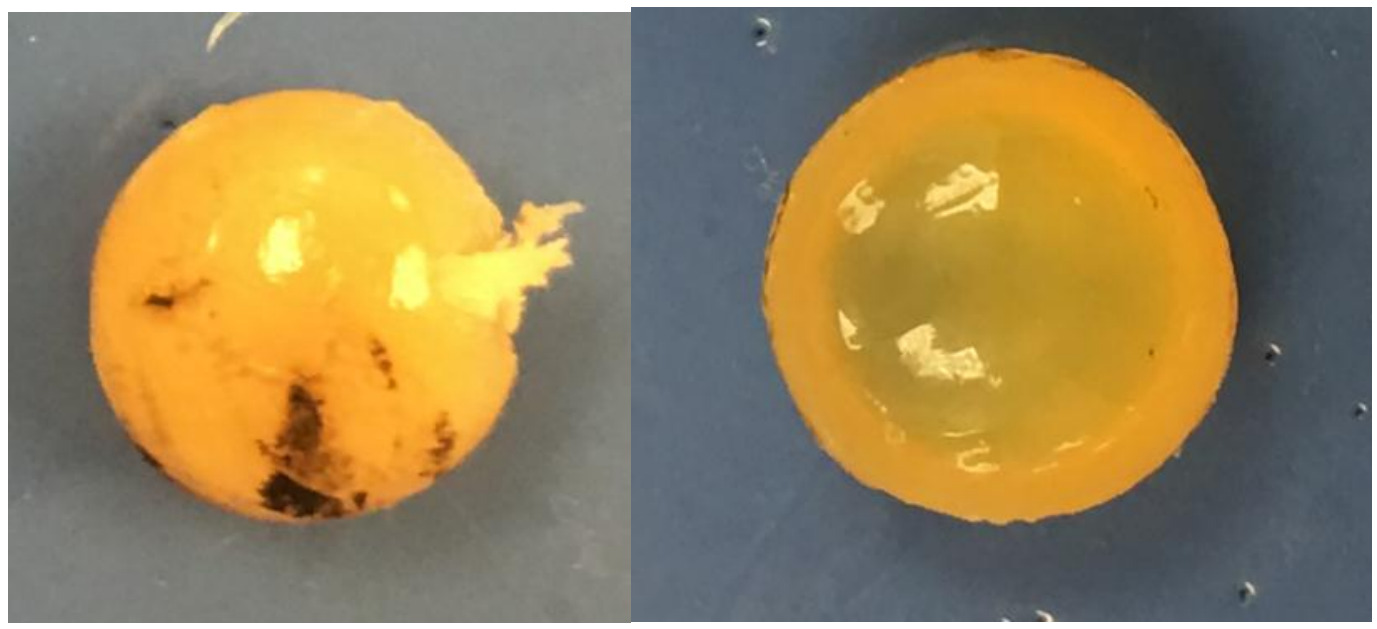

4. Now take the back half of the eye, and carefully attempt to remove the retina. It may still be attached via the optic nerve. Simply cut it away while attempting to maintain the retina in as large a peace as possible. If possible, divide it into two separate pieces and place it between tow microscope slides with a small amount of saline or distilled water.

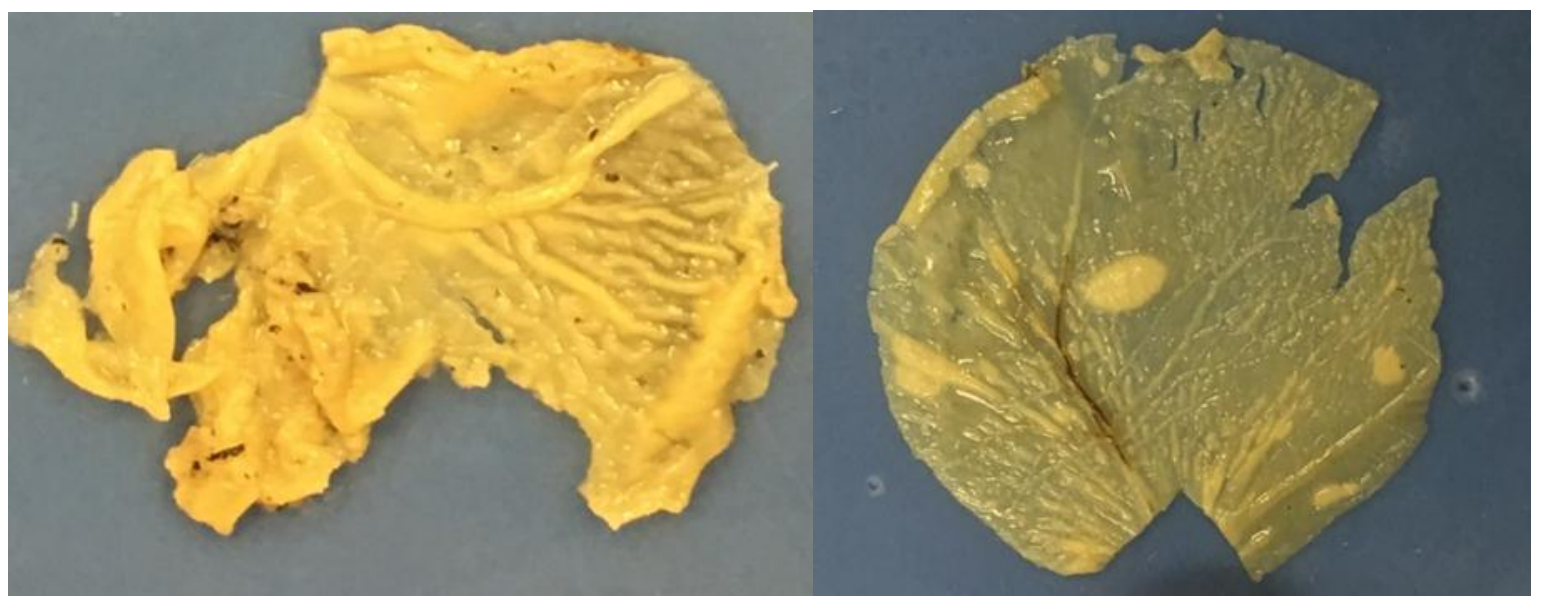

5. Label each sample of cow and sheep lens, and cow and sheep retina. You should have two lenses, and two retinas, separated into two samples each.

\section{This concludes the anatomy portion of the lab.}

\section{Part 2: Lens Experiment}

1. Begin by taking pictures, using the microscope and computer software, try to get a zoomed in, and zoomed out image of all samples of the lens.

2. Powers up the HeCd laser using the SOP and ensuring all participants in the room have proper eye protection.

3. Begin with an initial power reading of the laser output.

4. Obtain a beam diameter

5. Also take an initial temperature of the lens, as well as a detailed observation. Pictures would be a good idea.

6. Mount the lens in a way that allows for the beam to pass through, ensure proper beam stops are in place to control any reflections or refractions. 
7. Observe the lens and begin taking temperature reading using the IR thermometer.

8. If possible, take power measurements of the beam after it passes through the lens.

9. After taking sufficient measurements close the shutter, remove the lens, and note the temperature, and make detailed observations, as well as take pictures.

10. Document your findings in Table 1.

11. Shutdown Laser using SOP

\section{Part 3: Retina Experiment}

1. Begin by taking pictures, using the microscope and computer software, try to get a zoomed in, and zoomed out image of all samples of the retina.

2. Power up the IPG laser using the SOP and ensuring you follow all proper safety precautions.

3. Obtain an initial power reading.

4. Obtain a beam diameter.

5. Also take an initial temperature of the Retina, as well as a detailed observation. Pictures would be a good idea.

6. Mount the retina in the microscope slide in the beam path; ensure proper beam stops are in place to control any reflection.

7. Observe the retina and begin at 55\% power taking temperature reading using the IR thermometer, and looking for visible damage to the retina.

8. Repeat this step at $100 \%$ power with another sample.

9. Stop the laser emission as soon as damage is visible. Recording the time, and power setting.

10. Document your findings in Table 2.

11. Shut down Laser using SOP.

\section{Part 4; Data Collection}

Table 1: HeCd Laser/Lens

\begin{tabular}{|c|c|c|}
\hline & Cow Lens & Sheep Lens \\
\hline Initial Power & $5 \mathrm{~mW}$ & $5 \mathrm{~mW}$ \\
\hline $\begin{array}{l}\text { Initial beam } \\
\text { diameter }\end{array}$ & $1.0 \mathrm{~mm}$ & $1.0 \mathrm{~mm}$ \\
\hline Initial Lens temp & $68.3^{\circ} \mathrm{F}$ & $68.1^{\circ} \mathrm{F}$ \\
\hline $\begin{array}{l}\text { Initial Lens } \\
\text { Notes }\end{array}$ & $\begin{array}{l}\text { Cloudy, somewhat translucent, smooth, divided } \\
\text { into three equal segments meeting in the } \\
\text { middle. }\end{array}$ & $\begin{array}{l}\text { Cloudy, unable to see through, dark } \\
\text { pigmentation, side is damaged }\end{array}$ \\
\hline $\begin{array}{l}\text { 2-minute Lens } \\
\text { temp }\end{array}$ & $69.4^{\circ} \mathrm{F}$ & $69.0^{\circ} \mathrm{F}$ \\
\hline $\begin{array}{l}\text { 3-minute lens } \\
\text { temps }\end{array}$ & $69.6^{\circ} \mathrm{F}$ & $69.2^{\circ} \mathrm{F}$ \\
\hline $\begin{array}{l}\text { 5-minute lens } \\
\text { temps }\end{array}$ & $69.9^{\circ} \mathrm{F}$ & $69.2^{\circ} \mathrm{F}$ \\
\hline 40 minutes & $\begin{array}{l}\text { NO noted temperature increase, or visible } \\
\text { damage }\end{array}$ & \\
\hline $\begin{array}{l}\text { Power through } \\
\text { lens }\end{array}$ & $68.3^{\circ} \mathrm{F}$ & $68.3^{\circ} \mathrm{F}$ \\
\hline Final lens notes & NA & NA \\
\hline & NO notable changes noted & NO notable changes noted \\
\hline
\end{tabular}


Lens Photos:

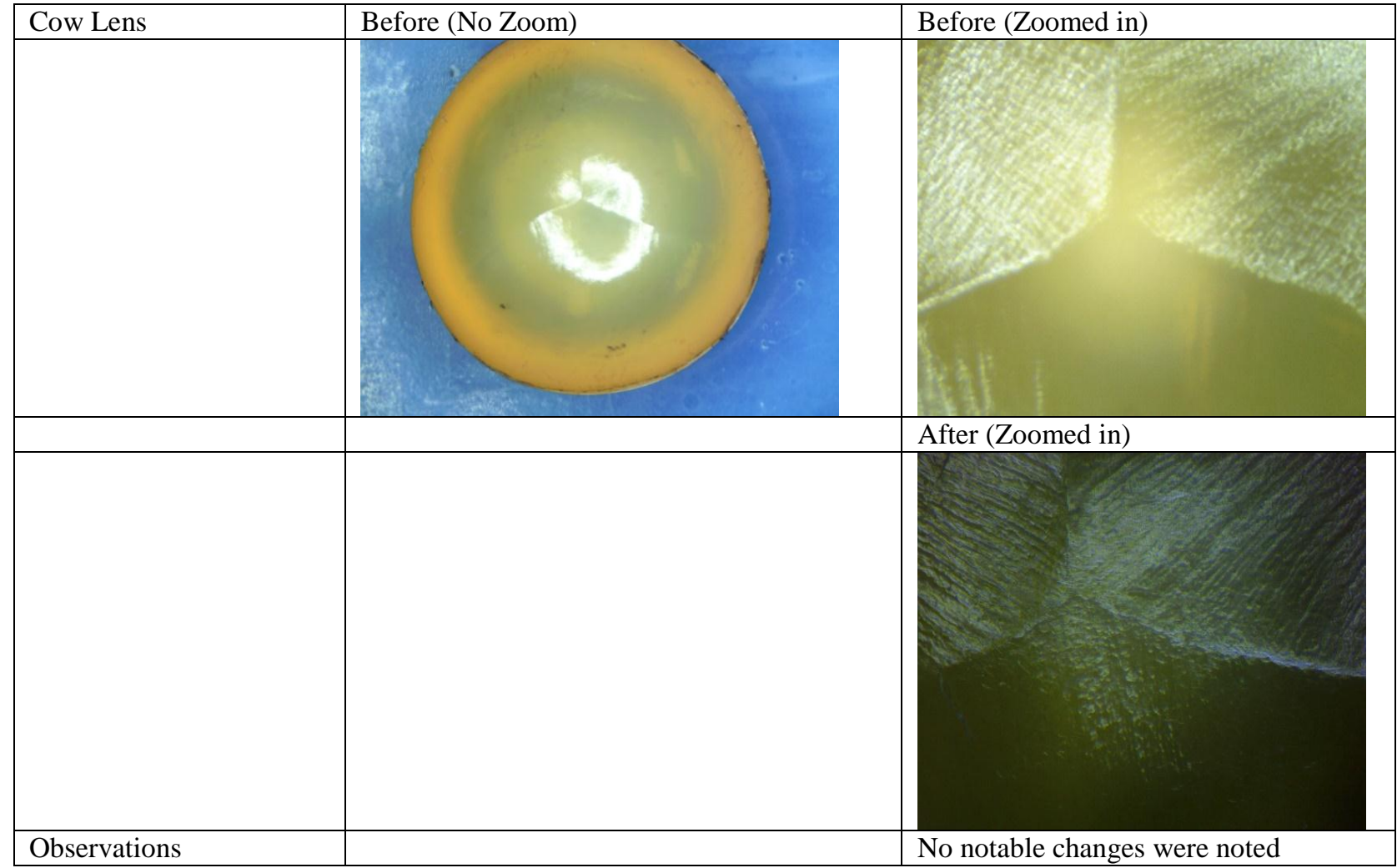

\begin{tabular}{|l|l|l|}
\hline Sheep Lens & Before (No Zoom) & Before (Zoomed in) \\
\hline & &
\end{tabular}


Table 2: IPG /Retina

\begin{tabular}{|l|l|l|l|l|}
\hline & Cow Retina 1 & Cow Retina 2 & Sheep Retina 1 & Sheep Retina 2 \\
\hline Initial Power & $4.2 \mathrm{~W}(55 \%)$ & $8.4 \mathrm{~W}(100 \%)$ & $4.2 \mathrm{~W}(55 \%)$ & $8.4 \mathrm{~W}(100 \%)$ \\
\hline Beam Diameter & $1 \mathrm{~mm}$ & $1 \mathrm{~mm}$ & $1 \mathrm{~mm}$ & $1 \mathrm{~mm}$ \\
\hline Initial Retina temp & $68.3^{\circ} \mathrm{F}$ & $68.5^{\circ} \mathrm{F}$ & $68.2^{\circ} \mathrm{F}$ & $68.1^{\circ} \mathrm{F}$ \\
\hline Initial Retina Notes & $\begin{array}{l}\text { Moist, opaque, off- } \\
\text { white color, } \\
\text { vasculature visible, } \\
\text { wrinkled } \\
\text { appearance }\end{array}$ & SAME & SAME & SAME \\
\hline 1-minute Retina temp & No Change noted & No Change noted & No Change noted & No Change noted \\
\hline Visible damage & 1min55sec & 45 sec & 1min43sec & 1min \\
\hline Final Retina notes & $\begin{array}{l}\text { Visible hole } \\
\text { burned into the } \\
\text { retina at the } \\
\text { incident spot of the } \\
\text { laser, pictures in } \\
\text { table below }\end{array}$ & $\begin{array}{l}\text { Visible hole } \\
\text { burned into the } \\
\text { retina at the } \\
\text { incident spot of the } \\
\text { laser, pictures in } \\
\text { table below }\end{array}$ & $\begin{array}{l}\text { Visible hole } \\
\text { burned into the } \\
\text { retina at the } \\
\text { incident spot of the } \\
\text { laser, pictures in } \\
\text { table below }\end{array}$ & $\begin{array}{l}\text { Visible hole burned } \\
\text { into the retina at the } \\
\text { incident spot of the } \\
\text { laser, pictures in table } \\
\text { below }\end{array}$ \\
\hline
\end{tabular}

\section{Retina Photos:}

\begin{tabular}{|l|l|l|}
\hline Cow Retina & Sample 1 Before (No Zoom) & Sample 1 Before (Zoomed in) \\
\hline & & \\
& & \\
& After (No Zoom) & After (Zoomed in) \\
\hline & Hole resembles a tear in the retinal tissue. \\
\hline Observations & $\begin{array}{l}\text { Distinct holes have been burned into the retail } \\
\text { tissue, cellular damage is catastrophic and eye } \\
\text { damage would most likely have been serious. }\end{array}$ & \\
\hline
\end{tabular}




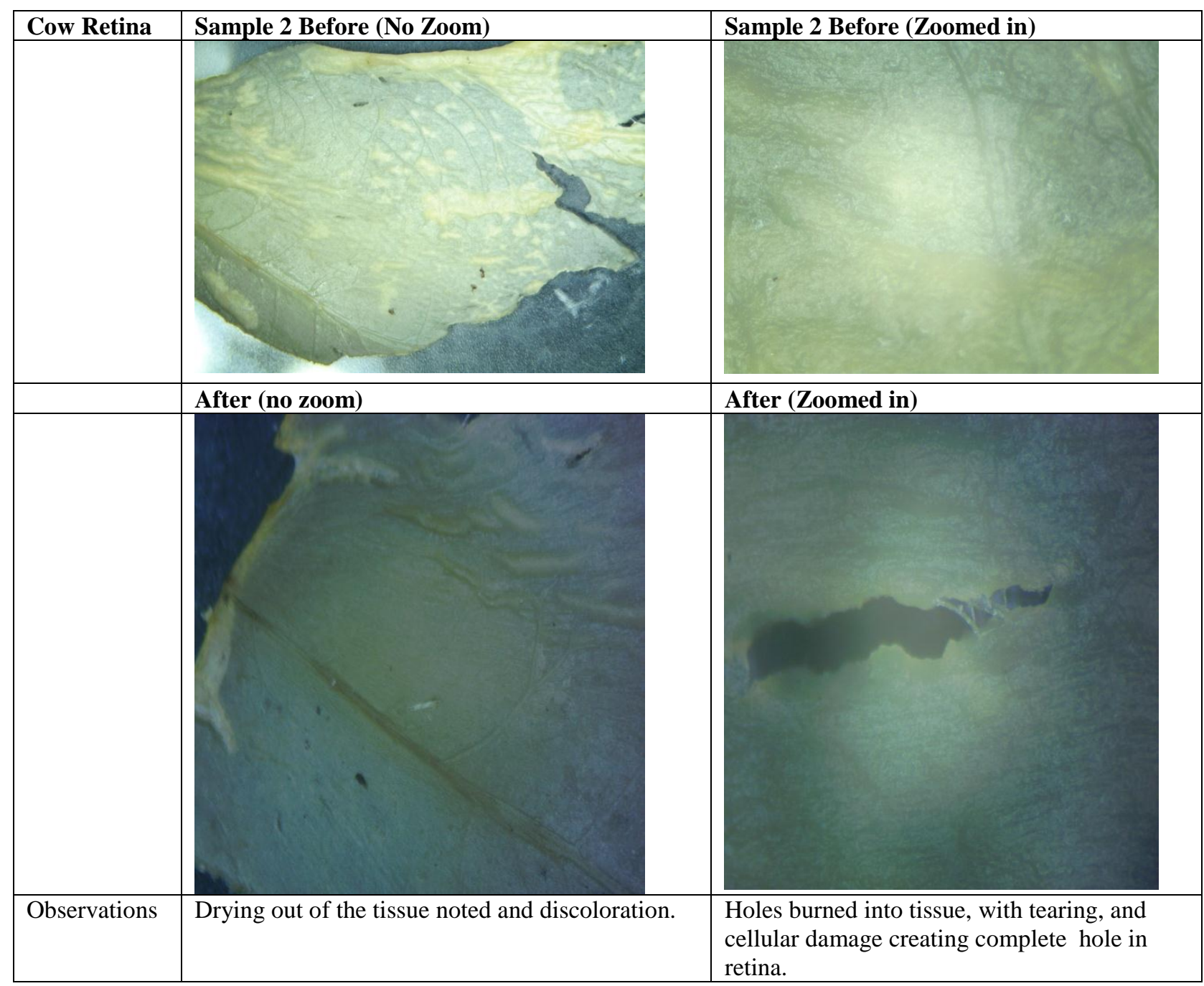

Proc. of SPIE Vol. $11143111433 \mathrm{~F}-10$ 


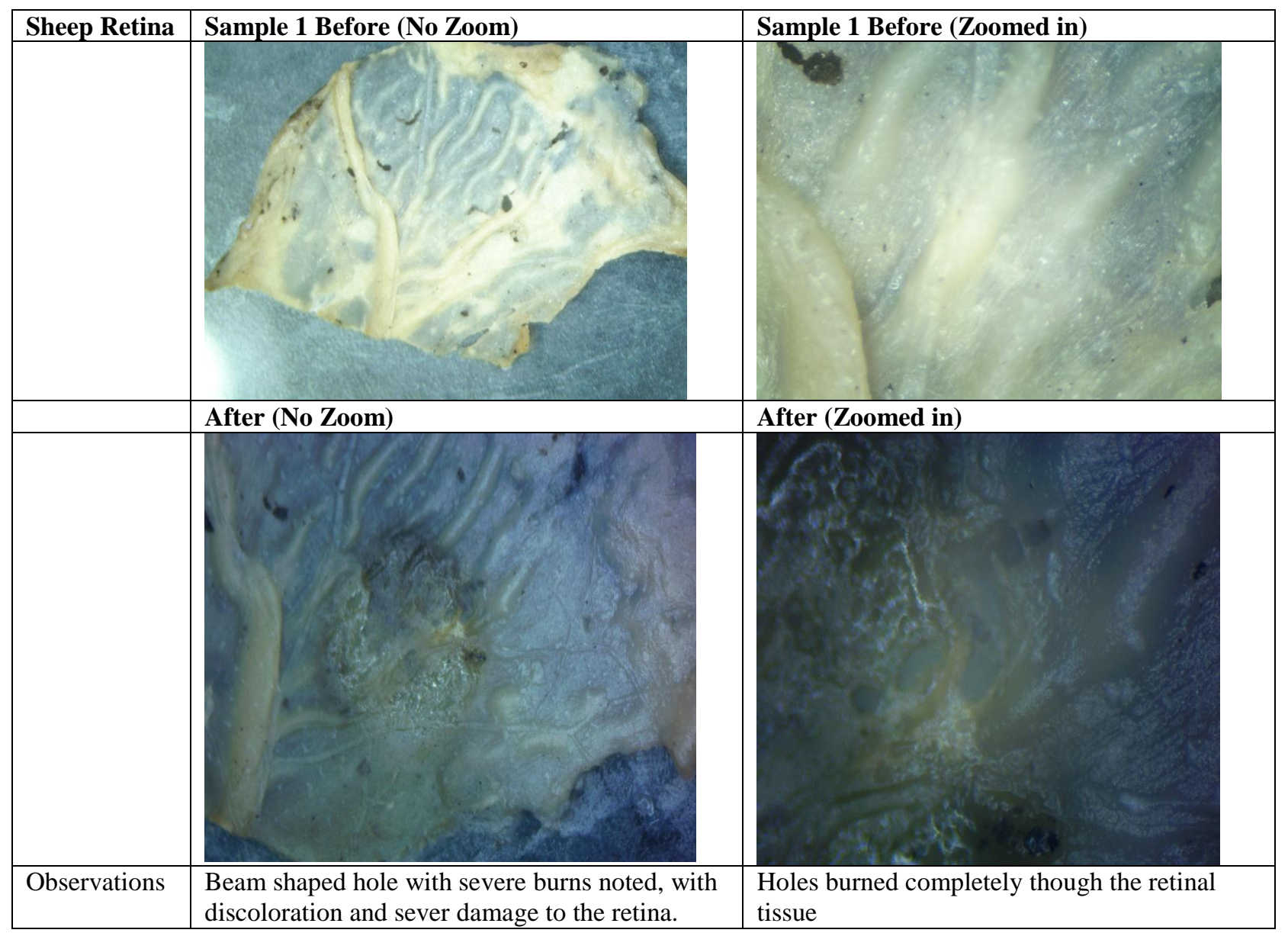




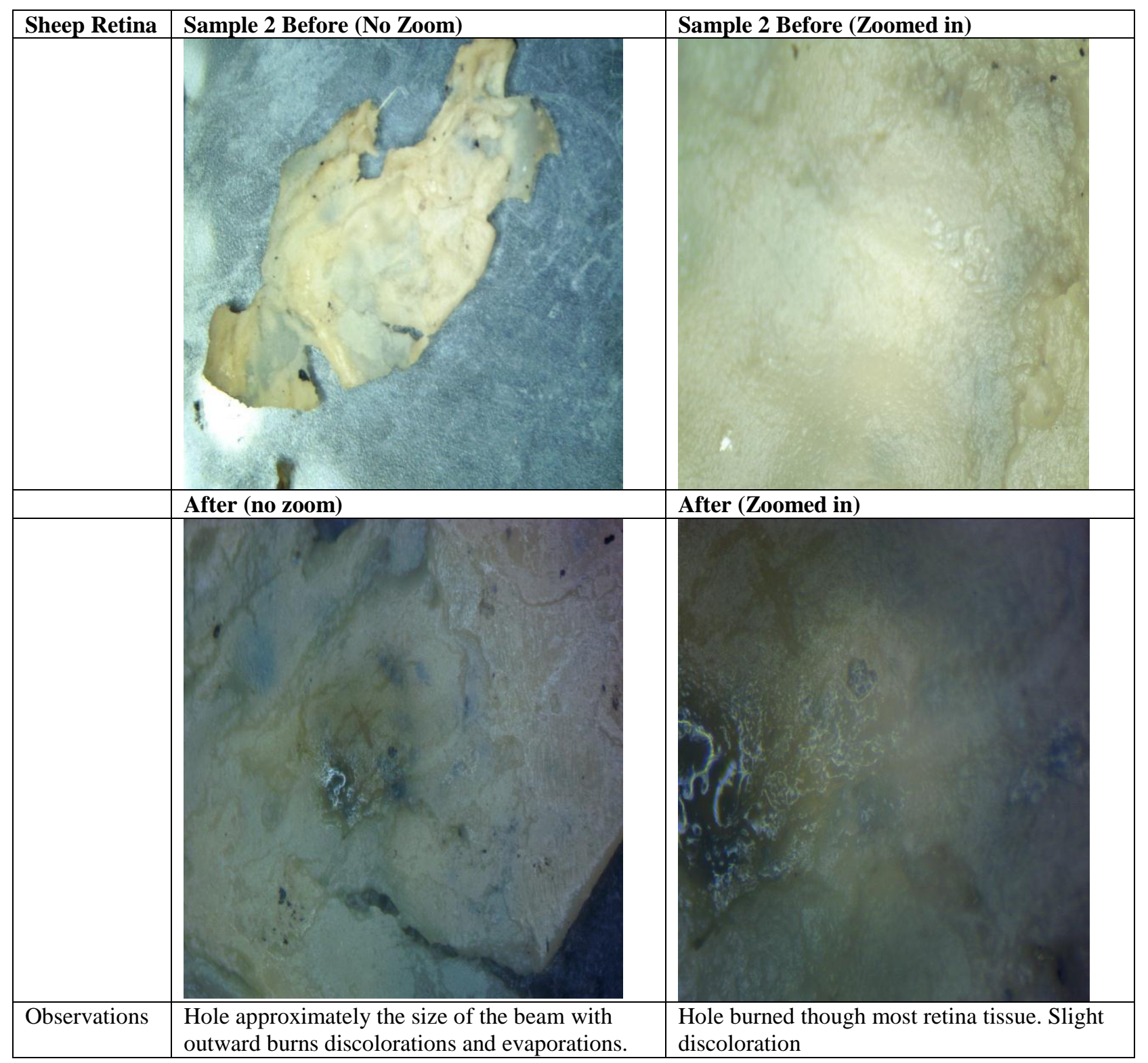

\section{Considerations:}

- The lens testing was not very informational. Some considerations that may have led to this are issues with the $\mathrm{HeCd}$ laser outputting a relatively low power $325 \mathrm{~nm}$ line. Also an inability to isolate this particular line in previous experiments could have added to the lack of results. It is possible the optical and cellular properties of the lens could have been altered in the preservations process.

- The initial concept was to measure the increase in thermal output of the parts of the eye. This was not a good source of information as the temperatures did not increase more than about 1 degree; this was possibly due to normal variances in the reading of the IR thermometers. As testing on various surfaces would regularly reveal differences of 1-3 degrees.

- This was not meant to be a definitive measure of the optical properties, absorption characteristics, or measurements of the metrics involved with laser eye safety. The overall goal of this experiment was simply to illustrate the destructive capabilities of lasers on the delicate structures of the human eye. 


\section{Conclusion:}

- The damage to the eye, in this scenario would be catastrophic and most likely permanent. One thing to keep in mind was that the retinal exposure from the IPG laser was not subject to the optical gain of the lens. If we use the equation for irradiance $=$ Power/Area, where $\mathrm{P}=$ power of the incident laser, in this case $\mathrm{P}=8.4 \mathrm{~W}$ for the IPG laser and $\mathrm{A}=$ area of the beam, which was $1 \mathrm{~mm}$ in diameter, $E=\frac{P}{A} \quad \mathrm{E}=\frac{8.4 \mathrm{~W}}{0.0079}=1070 \mathrm{~W} / \mathrm{cm}^{2}$. This is of course not considering the magnification of the lens which would focus the spot on to a much smaller area.

- Educationally this has the benefit of actually illustrating the damage possible to the eye. The time it took for the damage to occur was much longer than the average person would allow for an intra-beam viewing incident to occur. However with the optical gain of the human eye being around 100,000, the time it would take to permanently damage the retina in a real situation is significantly smaller.

- The significance of understanding and properly implementing the safety standards taught in the CCCC LPT program are more than just a module to read and test out of. The standards and procedures learned are for you, and your classmate's protection. Blindness and permanently altered vision are very real and irreversible possibilities, which can be avoided with proper education.

- The overall takeaway from the experiment, and lab developed around it, is that the retina, coupled with the lens, iris, and all other structures of the eye, work to bring the world around us in, via light, and allow us to process that light into images and sight. This also allows the potential danger, of laser light, if not properly respected, to use the same optical path our vision depends on to destroy, or damage at the very least, the delicate organs that we rely onto see. The damage notes in the photos, I have no doubt would cause serious visual impairment, if not blindness. It is with that knowledge that I have a deepened respect, and renewed emphasis on the importance of proper safety when working with lasers.

\section{END OF LAB}

\section{CONCLUSION}

The overall takeaway from the experiment, and lab developed around it, is that the retina, coupled with the lens, iris, and all other structures of the eye, work to bring the world around us, via light, and allow us to process that light into images and sight. This also allows creates potential danger, of laser light, if not safely used, to use the same optical path our vision depends on to destroy, or damage at the very least, the delicate organs that we rely onto see. The damage notes in the photos would definitely cause serious visual impairment, if not blindness.

This lab should help laser students to develop a deepened respect, and renewed emphasis on the importance of proper safety when working with lasers. 